\title{
Influencing Factors of NFDI Capital Volatility in the Process of Capital Account Liberalization
}

\author{
Lu Peng \\ School of Economics, Shanghai University, Shanghai, 200444, China \\ Woyaolizhixuexi@163.com
}

Keywords: Volatility of capital flows; Capital account liberalization; VAR model; Impulse response analysis

\begin{abstract}
This paper measured the influencing factors of NFDI capital volatility hope to prevent the risk of Capital Account Liberalization, while the Capital Account Liberalization has come to a substantive stage in China. Based on the existing literature, this article select the Sino US interest rate differential, onshore and offshore spreads, exchange rate expectations and capital account openness degree as four variables and analysis this four variables' influence on the Volatility of NFDI capital flows by the VAR model using the monthly data from 2006 to 2014. The results show that exchange rate expectations and capital account openness are the most significant factors, and when the national financial environment gradually stabilized, the influence will gradually decrease. So we suggest that the first thing is to speed up the reform of the exchange rate market, which can help to form a virtuous cycle of interest rates, exchange rates and capital account liberalization, and then the capital account liberalization will get twice the result with half the effort.
\end{abstract}

\section{Introduction}

Capital Volatility mainly refers to changes in the scale of capital or a reversal in the direction of international flow in a short time, it is an important dimension to describe capital flows. Lucas (Lucas, 1990)[1] argued that the emerging market countries tend to have a higher return on investment than the international level, which will attract a large number of international capital into the domestic financial markets and the real economy in the process of promoting capital account liberalization. However, once the economic development trend is reversed, the profit-driven capital quickly will be quickly evacuated and swept away massive financial resources, which will produces devastating impact on emerging markets. This process occurred repeatedly in recent decades in the history of capital account liberalization, It is the fundamental reason for these countries to be cautious about the risk of capital account Liberalization. In the financial crisis outbreak in late 90 s of last century, the capital into emerging market countries sustained increase, and suddenly suffered reversal and decline, and the volatility of NFDI is the largest.

\section{Literature Review}

Foreign scholars mainly focus on interest rates and herd behavior of international investors in the study of external factors affecting the volatility of capital flows. According to Fernando\& Rigobon (2004)[2], Firat Demir(2009)[3], the empirical results show that external factors especially the interest rate spread at home and abroad is the main cause of capital flowing to emerging industrialized countries. Akihisa Shibata \& Mototsugu Shintanib(1998)[4] regressed 1970-2000 years country data and show that the bad policy can largely explain the strong capital volatility on the sample period. Li Jie (2015) [5] argued that the main determinants of capital volatility is interest rates, stock market yields and herding. ScottW. Hegerty(2011)[6] found that Latin American flows seem to experience more of a reduction in volatility due to increased openness, suggesting that this region enjoys more risk-sharing as a result of financial integration than do transition economies. Rebecca M (2008)[7] found Different types of capital flows are found to respond differently to financial liberalization. Surprisingly, portfolio flows appear to show little response to capital liberalization while foreign direct investment flows show significant increases in volatility, 
particularly for the emerging markets considered.

Domestic research on capital variability is relatively less, the spotlight on determining factor of capital flows volatility, the volatility characteristics of constituent part of capital flows and the impact on macroeconomic is not enough. The most representative research is conducted by $\mathrm{Li} \mathrm{Ze}$ Guang(2003)[8], He designed capital coefficient of variation to measure the volatility of capital and analyzed the macroeconomic effects of capital volatility Wang Wei (2007) [9] adopted Time and point measurement method to measure the volatility of various components of capital flows. Besides, he estimated and discussed the relationship between the volatility of international capital flows and macroeconomic variables. Wenxi Zhang(2007) [10]established General equilibrium models for developing country and developed country respectively, and conducted empirical study of the factors of NFDI capital volatility. Xie Shouqiong (2009)[11] describes the causes of international capital volatility and its influence on the stability of financial markets. Han Jian (2012) [12] adopted GARCH model and tested the determinants of volatility with panel data and found that the structure of the domestic financial system, exchange rate fluctuations and inflation determine the NFDI capital volatility.

However, there are following shortcomings in related research: First, the measurement index of the capital flows volatility is still controversial; Second, researches have focused on different situation in different countries, there are less researches on the factors affecting the volatility of capital flows in the process of Capital Account Liberalization in our country ; Third, the description of the dynamic relationship between the capital flows volatility and relative factors in those model is not enough. Therefore, this paper utilized the capital flow coefficient of variation (coefficient of variation, CV) indicators build by Li zeguang (2003) to measure our monthly international capital flow volatility, and selected VAR model to observe the dynamic relationship between each factor variable and capital flows volatility, besides, this article added the onshore and offshore interest spreads into our model.

\section{Model and Data}

This paper selected the monthly data from 2006 to 2014, the sample size will be greater by using monthly data instead of annual data. And the estimation accuracy of VAR model will be higher, which can better reflect the dynamic fluctuation of capital flows volatility. This paper selected Sino US spreads AC, onshore and offshore spreads OF in terms of interest rates; chosen exchange rate expectations EX in terms of exchange rate; and utilized OPEN to represent the capital account openness. Calculation of the index is as follows:

$C V_{t}=2\left|K_{t}-K_{t-1}\right| /\left(K_{t}+K_{t-1}\right)$

$K_{t}$ is on behalf of net inflows at time t, and represents net inflows of NFDI in this paper. And NFDI capital $=$ Increase in foreign exchange reserves - trade surplus - Foreign Direct Investment

\section{Empirical Analysis}

Each sequence passed through the stationary test from the result of Table 1, thus all the index can be used in this VAR model.

Table 1 The test results of five variables

\begin{tabular}{cccc}
\hline Variables & statistical values of $\mathrm{Z}$ & $\mathrm{P}$ value & Conclusion \\
\hline CV & -10.621 & 0.0000 & Stationary process \\
AC & -10.868 & 0.0000 & Stationary process \\
OF & -15.858 & 0.0000 & Stationary process \\
EX & -6.951 & 0.0000 & Stationary process \\
OPEN & -12.719 & 0.0000 & Stationary process \\
\hline
\end{tabular}


Based on the estimation of VAR model, the impact period was set for 8. And impulse response analysis is as follows:

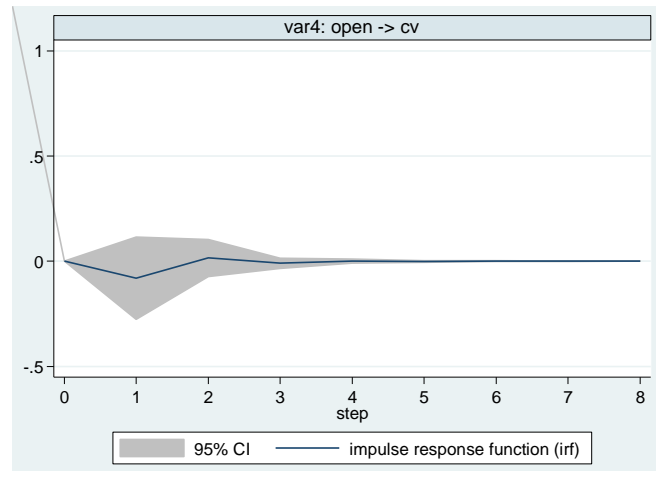

Figure 1. Capital volatility

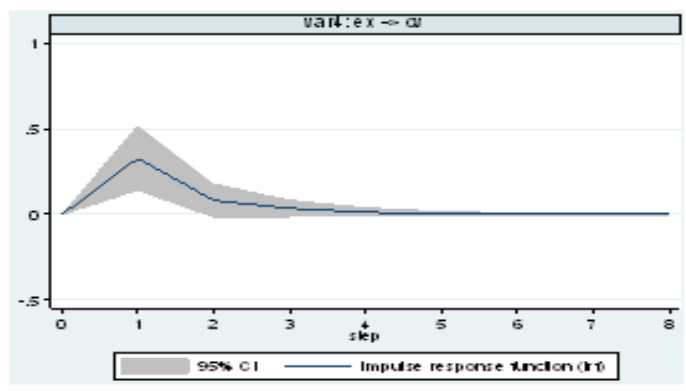

Figure 3. Interest rate expectation

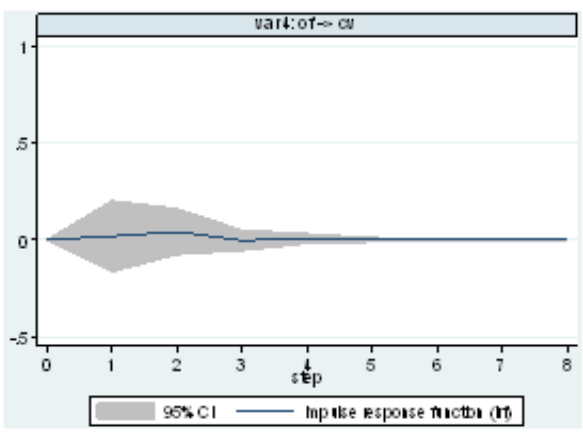

Figure 2. Onshore and offshore spreads

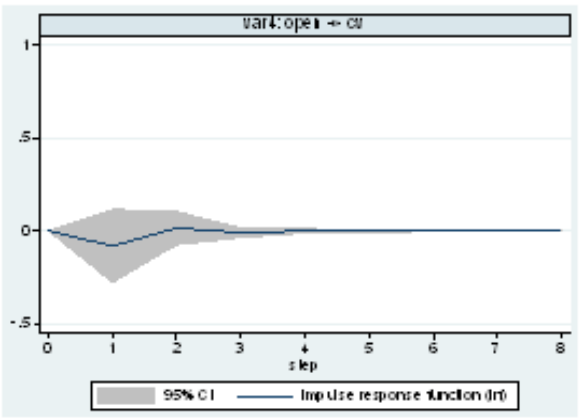

Figure 4. Capital account openness degree

When 1 units of positive shock of CV occurred, the response reaction of itself is maximum in the current period, and becomes less negative in the first phase of the -0.89 , second turn to less positive 0.017, gradually tends to zero in 3 period. This shows that the response reaction of capital flows volatility has about 3 months inertia, but in the long term, the flow direction constantly change with poor predictability, which is consistent with its general characteristics

When 1 units of positive impact of EX occurred, the response reaction of $\mathrm{CV}$ is maximum in the 1 period, and gradually did not influence the $\mathrm{CV}$ after fifth period. And the response reaction is positive in the long term. This indicated that the exchange rate expectation greatly impact on the capital flows volatility, and last for a long time. Because Volatility of capital flows depends largely on the direction and scale of short-term capital flow, and short-term capital mainly rely on the exchange rate expectation to drive.

When 1 units of positive impact of OPEN occurred, the response reaction of CV is maximum in the 1 period, and is negative in second period. The opening of capital account in the beginning will have great impact on $\mathrm{CV}$, and the impact can be positive or negative on the first and the second period, which cannot be predicted, but with the opening of the capital account continues to advance, and the national financial environment gradually stabilized, the influence of Capital Account Liberalization on capital flows volatility will gradually decrease.

\section{Conclusions}

Through the impulse response analysis, we found that, firstly, the offshore and onshore interest rates spread can drive short-term arbitrage capital flow greatly compared to Sino US interest rate differential, and this because the Chinese interest rates yet not fully market-oriented, at the same time, it also can provide theoretical support for the establishment of Shanghai offshore financial center for Chinese; secondly, compared to the interest rate, exchange rate have more influence on the capital flow volatility, it reminded the authorities that they should conduct effective policy to 
guide public expectations reasonable; finally, the capital account liberalization would influence capital flows volatility in short-term, and this effect is unpredictable, But with the continuous and stable financial environment, this effect will decrease gradually, therefore, we should be in a reasonable way to promote capital account liberalization, be prudent to conduct risk prevention in the process of capital account liberalization.

In conclusion, we suggest that the first thing is to speed up the reform of the exchange rate market, which can help to form a virtuous cycle of interest rates, exchange rates and capital account liberalization, and then the capital account liberalization will get twice the result with half the effort.

\section{References}

[1] Lucas R E. Why doesn't Capital Flow from rich to poor countries [J]. American Economic Review, 1990, 80(2): 92-96.

[2] Firat Demir. Volatility of Short-term Capital Flows and Private Investment in Emerging Markets [J]. Journal of Development Studies, 2009, 45(5): 672-692

[3] Fernando A. Broner \& Roberto Rigobon. Why are capital flows so much more volatile in emerging than in developed Countries [J] Social Science Electronic Publishing, 2004:15- 39.

[4] Akihisa Shibata \& Mototsugu Shintanib. Capital mobility in the world economy: an alternative test [J]. Journal of International Money \& Finance, 1998, 17(5):741-756

[5] Jie Li, Ramkishen S. Rajan. Do capital controls make gross equity flows to emerging markets less volatile? [J]. Journal of International Money and Finance, 2015, 59-60.

[6] ScottW. Hegerty. Openness and capital flow volatility: comparisons between transition economies and Latin America [J]. Applied Economics Letters,2011, 18(12):1177-1180

[7] Rebecca M. Neumann, Ron Penl, Altin Tanku. Volatility of capital flows and financial liberalization: Do specific flows respond differently? [J]. International Review of Economics and Finance, 2008, 183-184.

[8] Li Zeguang, Fu Fei, Tang Weixia. The analysis of the capital flow volatility and its economic effect [J]. financial research, 2003,12:11-17.

[9] Wang Wei. The volatility of international capital flows: measure, effect and management [D]. Xiamen University, 2007.

[10] Yu Shanping, Zhang Wenxi. Measurement of the volatility of non FDI capital inflow in China [J]. Journal of Southeast University (PHILOSOPHY AND SOCIAL SCIENCES), 2008, 05:14-18+126.

[11]Xie Shouqiong, Yan Wei. The influence of the volatility of international capital flows to Chinese financial market stability [J]. Development research, 2009, 05: 32-34.

[12] Han Jian. Study on the volatility of international capital inflow and Its Countermeasures [J]. international financial research, 2012,05:66-73. 